\title{
IV. RESEÑAS
}

\section{LA CARNE Y LA METÁFORA. UNA REFLEXIÓN SOBRE EL CUERPO EN LA TEORÍA QUEER}

Autor: Gerard Coll-Planas

Editorial Egales, Barcelona, 2012

\section{Gloria Álvarez Bernardo ${ }^{1}$ \\ gloab@ugr.es \\ Universidad de Granada}

Recibido: 13-09-2014

Aceptado: 11-04-2015

Desde determinados sectores académicos queer, el cuerpo se ha presentado como una construcción cultural, minimizando y, en algunos casos, negando su base biológica. En este libro, Gerard Coll-Planas trata de analizar las implicaciones que la teoría queer tiene en relación a la materialidad del cuerpo. Lo que el autor plantea es cómo se puede interpretar el cuerpo material (aquel que tiene una base física irrefutable) y el cuerpo metafórico (aquel que es resultado de un proceso de inscripción cultural, de negación corpórea). La disyuntiva entre estas dos opciones abre un interesante debate acerca de las posibilidades y los límites de las expresiones teóricas queer como parte de un discurso práctico para la acción y reivindicación política.

Para ahondar en este debate, a lo largo de los dos primeros capítulos de La carne y la metáfora, Coll-Planas plantea diferentes historias que se entrecruzan y que ponen de manifiesto

\footnotetext{
${ }^{1}$ Diplomada en Trabajo Social por la Universidad de Oviedo. Licenciada en Antropología Social y Cultural por la Universidad Rovira i Virgili. Premio Extraordinario Fin de Carrera (2009). Premio Nacional a la Excelencia en el Rendimiento Académico Universitario (2010). Becaria FPU del Ministerio de Educación.
} 
las posibilidades y los límites del cuerpo. La primera selección de ejemplos explora los usos corporales como una respuesta que ahonda en motivaciones diversas que van desde lo estético hasta lo performativo. Las operaciones quirúrgicas son una muestra de ajuste del cuerpo a los cánones de belleza mayoritarios. Asimismo, estas operaciones pueden convertirse en una performance sobre la que inscribir deseos y aspiraciones personales o sobre las que trazar una obra artística. El cuerpo se transforma en un receptáculo que trata de superar, retar o combatir sus propios límites e, incluso, cuestionar su propia materialidad. La cultura impregna a los cuerpos de significado civilizatorio tratando de negar cualquier resto de su pátina natural, biológica. Sin embargo, el cuerpo (con su esencia orgánica y personal) perdura y esto se puede constatar en aquellos hechos que escapan a la voluntad y al control humano, entre ellos la muerte.

El segundo capítulo reflexiona sobre los límites corporales, en particular, los cuerpos que sufren, son violentados, vejados, que fallecen. El punto de partida se sitúa en el asesinato de dos jóvenes en Galicia en el año 2006. El asesino confesó que el motivo que le llevó a cometer el asesinato fue el miedo a la violación masculina. Tanto de este miedo como del crimen pertrechado se puede deducir que los cuerpos están expuestos a múltiples experiencias, algunas de las cuales resultan ser angustiosas, deplorables, espantosas (como es el caso del dantesco escenario del asesinato). En actos como éstos es donde el cuerpo expresa su dimensión material y humana, su carácter intrascendente y limitado.

De un modo suficientemente explícito, el autor nos presenta una serie de vivencias que reflejan la vulnerabilidad del cuerpo humano, de cómo los presupuestos teóricos no siempre se encuentran en disposición de explicar las penurias a las que se han de enfrentar los cuerpos reales, de carne y hueso. El dolor experimentado por la madre de uno de los chicos asesinados (por su desaparición física, corporal) contrasta con las afirmaciones de un cierto sector de teóricos queer que propugnan que el cuerpo no existe, que se trata de un simbolismo, de una metáfora. El sufrimiento materno, en este caso, no entiende de tales figuras lingüísticas.

En este punto se inicia el capítulo tercero donde Coll-Planas plantea las limitaciones subversivas del discurso queer cuando éste niega a las personas su dimensión física para convertirlas en voluntad eterna e ilimitada. La abolición irrefrenable de las categorías identitarias propugnadas por el discurso hegemónico, así como la aceptación de aquellos comportamientos no normativos (violación, pederastia o necrofilia, entre otros) favorecen la desarticulación de la lucha que trata de combatir los problemas diarios de personas que se ven 
atravesadas por las múltiples violencias ejercidas sobre sus cuerpos. Minusvalorar, o ignorar, la dimensión física del cuerpo es una de las lecturas queer - a la obra y al pensamiento de Judith Butler, principalmente- en la que se tiende a primar el carácter metafórico sobre el material y, con ello, se debilita la lucha política colectiva al tratarse de actos en los que se prescinde de un vínculo vertebrador compartido. En esta línea se ubica el pensamiento y la obra de Beatriz Preciado para quien el cuerpo es lenguaje y, desde su punto de vista, las personas gozan de un amplio margen de maniobra para operar sobre sus cuerpos, para jugar con el lenguaje. Sin embargo, apunta Coll-Planas, el margen no es tal si se tienen en cuenta las múltiples vicisitudes a las que están expuestos los cuerpos como realidades físicas, entre ellas el sufrimiento o la muerte que marcan los límites de la propia voluntad y autonomía personal.

Por último, en el capítulo cuarto el autor realiza una crítica a ciertas propuestas formuladas por colectivos queer en el territorio español. Algunas de ellas abordan aspectos tan polémicos y controvertidos como la aceptación de aquellos comportamientos que se sitúan al margen de lo normativo y que connotan violencia o degradación de uno mismo o de otras personas. Señala el autor la necesidad de marcar límites, así como elaborar un programa político que trascienda la mera subversión simbólica y que, en cambio, articule un conjunto de medidas políticas factibles que permitan actuar para procurar cambios reales y estructurales. Más allá de la burla o de la descalificación hacia la masa no activista queer, en la que se centran ciertas propuestas, es preciso buscar puntos de encuentro para el diálogo y la acción conjunta. Para lograrlo hay que tener en cuenta la influencia que las estructuras sociales ejercen sobre la configuración de nuestra propia identidad ya que éstas permiten atajar los miedos e inseguridades que derivan de una sociedad sin categorías a las que aferrarse. La libertad y el poder de las personas son limitados, de ahí que sea necesario reconocer estas restricciones para poder propiciar la transformación. En esta confusión, entre lo que somos y lo que nos gustaría ser, es donde deben buscarse las herramientas políticas adecuadas para combatir el orden represor, siendo conscientes de las limitaciones personales y del alcance de nuestros actos.

La carne y la metáfora suscita una lectura crítica del entramado teórico queer, en particular de sus límites explicativos y de su orientación academicista. El relato de experiencias e historias reales permite establecer una conexión con el dolor y la violencia, con las restricciones éticas, así como con las limitaciones corporales físicas y su margen de acción simbólico, algo olvidado en ciertas corrientes queer. Por tanto, se trata de una obra original, crítica y capaz de dar una novedosa vuelta de tuerca a una teoría que parece ser sólo eso, por su 
falta de acción y compromiso político con quienes experimentan la tragedia en sus carnes, más allá de lo metafórico. La veracidad que transmite, hace de la obra un relato que trasciende el ámbito académico para abrir un espacio de debate colectivo acerca de la viabilidad de un programa político queer, punto resuelto con acierto en su epílogo.

\section{BIBLIOGRAFÍA}

- Coll-Planas, Gerard (2012): La carne y la metáfora. Una reflexión sobre el cuerpo en la teoría queer. Barcelona: Egales. 